Proceedings of the 10th International Ruminant Reproduction Symposium (IRRS 2018); Foz do Iguaçu, PR, Brazil, September 16th to 20th, 2018.

\title{
Factors influencing establishment of the ovarian reserve and their effects on fertility
}

\section{Danielle Monniaux*}

UMR Physiologie de la Reproduction et des Comportements, INRA, CNRS, IFCE, Université de Tours, 37380 Nouzilly, France.

\begin{abstract}
A reserve of primordial follicles is set up in the ovaries of fetuses or neonates, depending on the species, and serves as the source of developing follicles throughout the reproductive lifespan. This review focuses on the cellular and molecular mechanisms currently known to control the establishment of this reserve, and their regulation by environmental factors. Most mutations in genes controlling germ cell proliferation and survival, meiosis or follicle assembly lead to the absence of primordial follicles or a sharp reduction in their number, incompatible with fertility in adults. Inadequate maternal nutrition affects the cellular metabolism, increases the oxidative stress and delays follicle formation in fetal ovaries. Despite the existence of compensation mechanisms of some developmental processes, the early-life nutritional environment imprints the long-term ability of follicles to enter growth and develop in adult ovaries. However, maternal undernutrition, overfeeding or high-fat diet during the establishment of the ovarian reserve does not seem to affect the fertility of the female offspring, unless their metabolism or neuroendocrine status is altered. Exposure of fetal or neonatal ovaries to excess steroids inhibits or stimulates follicle formation in a complex manner depending on the nature of the steroid, the dose and the animal species. Estrogens can control follicle formation through intra-ovarian mechanisms involving members of the TGF-beta family such as activin and BMP2. Early-life exposure to synthetic estrogens or environmental pollutants with estrogen-like activity impairs meiotic progression and follicle assembly, and affects long-term primordial follicle activation in adult ovaries. The effects of compounds with estrogen-like activity on the ovarian reserve can be transmitted to several generations through the female germline. Further investigations are needed to establish the earlylife effects of the environmental factors on the female reproductive lifespan and decipher the mechanisms of their epigenetic effects on the size and quality of the ovarian reserve.
\end{abstract}

Keywords: cyst breakdown, germ cells, oocyte, ovary, primordial follicle.

\section{Introduction}

In the ovary, the growing follicles develop from a reserve of primordial follicles constituted early in life and gradually emptied by both follicle growth activation and follicle degeneration. From this first reserve of primordial follicles, a second ovarian reserve is formed, which consists of gonadotropin-responsive small antral growing follicles and is a dynamic reserve for ovulation. The mechanisms regulating the transitions between reserves have been recently reviewed (Monniaux et al., 2014).

When established, the reserve of primordial follicles is oversized in all species. For instance, in the fetal bovine ovary at the end of the first trimester of pregnancy, it comprises millions of follicles (Erickson, 1966), of which only some hundreds of them will grow up to the ovulatory stage during the postnatal life. An intriguing observation is that the size of the ovarian reserve in the early postnatal life varies importantly between individuals of the same species or strain (sheep: McNatty et al., 1995; pig: Black and Erickson, 1968; humans: Block, 1952; Baker, 1963; Forabosco and Sforza, 2007). Recently, Ireland et al working on cattle reproduction proposed that the maternal environment has a critical role in regulation of the inherent high variation in the ovarian reserve. Moreover, they raised the important question: does size matter in females? and argued that young adults with a low ovarian reserve of primordial follicles have low numbers of growing follicles and phenotypic characteristics usually associated with ovarian aging and infertility (Ireland et al., 2011). How the establishment of the first reserve during the fetal or the early postnatal life can affect in a sustainable way the quality and growing features of the follicles of the second reserve, and finally the female fertility in adult life, remains a challenging question, however.

This review will outline the different steps of the establishment of the reserve of primordial follicles and our current knowledge of the molecular and environmental control of this set up. From recent data available in different animal models and in humans, we will try to understand how the environmental factors may regulate the size of the ovarian reserve and the developmental capacity of the primordial follicles, and discuss their possible long-term effects on female fertility and longevity of reproduction.

\section{Main steps of ovarian reserve establishment}

The setting up of the reserve of primordial follicles occurs through similar mechanisms in all mammals, but the timing of the processes underlying the formation of the reserve is species-specific (Monniaux et al., 2014; Fig. 1). Gonad morphogenesis involves the invasion of the genital ridge by mesonephros-derived cells, which associate with a founder population of primordial germ cells (PGC), as demonstrated in sheep and cattle (Zamboni et al., 1979; McNatty et al., 2000; 
Hummitzsch et al., 2013). Upon arrival at the gonad, the germs cells, named oogonia at this stage, enter synchronous mitotic divisions with incomplete cytokinesis, forming clonal cell clusters named germ cell cysts or nests, as shown in mouse (Pepling and Spradling, 1998). While the oogonia are dividing to form cysts, they also interact with somatic cells in the ovary. The germ cells and epithelial pre-granulosa cells become organized into ovigerous or ovarian cords, outlined by a basement membrane that separates them from the mesenchymal cells of the developing ovary.
The ovigerous cords are notably well developed in sheep and cattle and they remain until primordial follicles begin to form (Juengel et al., 2002; Sawyer et al., 2002; Burkhart et al., 2010; Garverick et al., 2010; Hummitzsch et al., 2013). At this stage of intensive mitotic activity of oogonia, the number of germ cells increases exponentially up to about 15000 per ovary in mouse (Myers et al., 2014), 2700000 in cow (Erickson, 1966), 500000 to 1000000 in sheep (Smith et al., 1993) and more than 5000000 in humans (Baker, 1963).
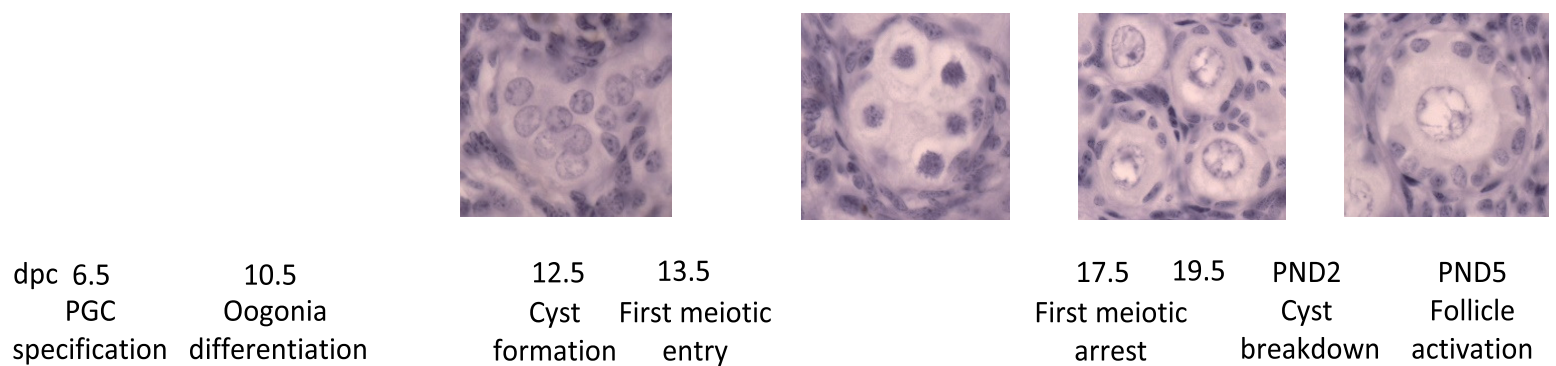

pecification differentiation formation entry

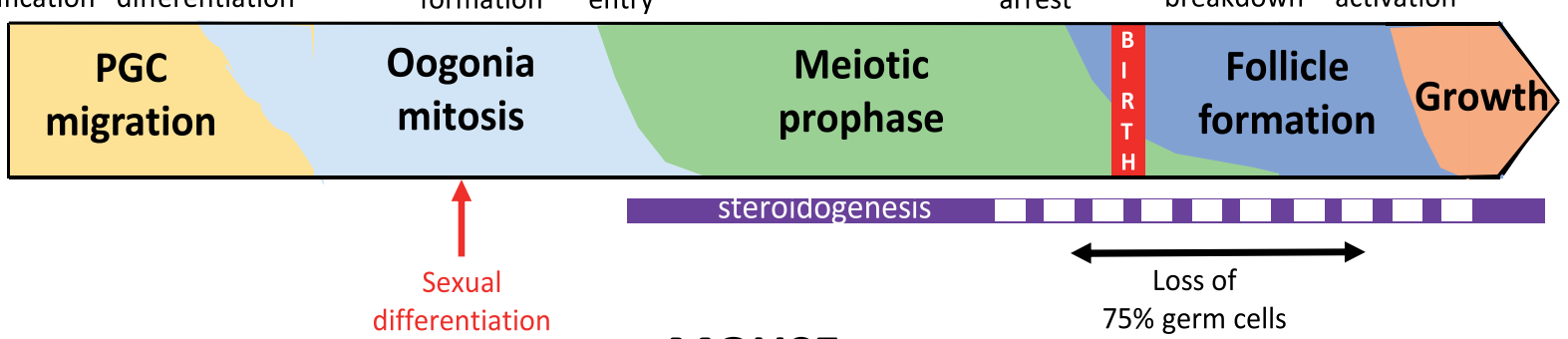

MOUSE

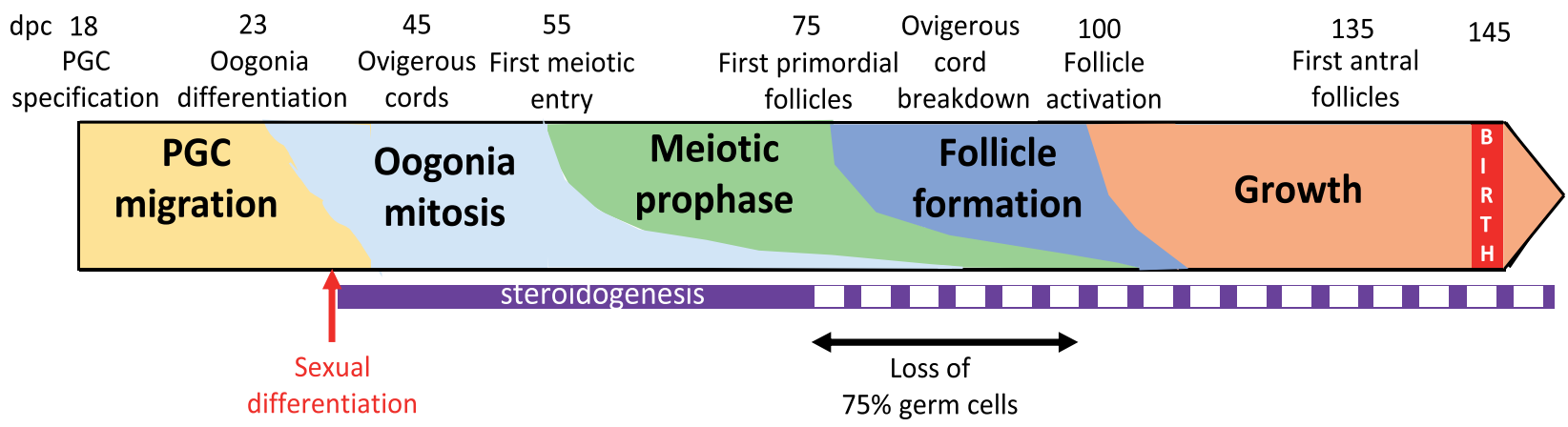

\section{SHEEP}

Figure 1. Timeline of the different steps of primordial follicle formation and activation in mouse and sheep ovaries. The periods of ovarian steroidogenesis activity are indicated in purple (full line: high activity, dotted line: low activity). Photographs illustrate the histological appearance of germ and somatic cells from germ cell cyst formation to the primary follicle stage (Monniaux and Brisard, 2018; INRA, Nouzilly, France; unpublished pictures). From Dutta et al., 2014; Findlay et al., 2015; Grive and Freiman, 2015 for mouse and McNatty et al., 1995; Quirke et al., 2001; Juengel et al., 2002 for sheep. PGC: primordial germ cells; dpc: days post-conception.

After cessation of mitosis, the oogonia enter meiosis and become oocytes, which progress through the stages of meiotic prophase I arresting in the diplotene stage. Afterwards, the germ cell cysts break apart and individual oocytes become surrounded by granulosa cells forming primordial follicles. It is estimated that during cyst breakdown, about $75 \%$ of the oocytes are lost through programmed cell death, including apoptosis and autophagy, as demonstrated in mouse (Pepling and Spradling, 2001; Rodrigues et al., 
2009).

The functional significance of germ cell development in the mouse cysts was unknown until recently. Using lineage tracing, Lei and Spradling investigated how the mouse germ cells are physically connected to one another and they observed centrosomes, Golgi material, and mitochondria traveling through large gaps in the plasma membrane and accumulating as a Balbiani body in a subset of oocytes during mouse perinatal oocyte development. These Balbiani bodycontaining oocytes survive and give rise to mature oocytes whereas the oocytes without Balbiani bodies would be only nurse cells as they look smaller, lose most of their cytoplasm, and appear to undergo apoptosis (Lei and Spradling, 2016). Each oocyte is associated with about four nurse cells (Pepling, 2016), that accounts for the dramatic loss of germ cells occurring during cyst breakdown. It appears that this development step determines in a large part the size of the reserve of primordial follicles and their ability to develop.

The formation of follicles proceeds centrifugally from the interface of the cortex and medulla towards the outer region of the cortex, as shown in humans (Konishi et al., 1986), rodents (Hirshfield, 1992; Mork et al., 2012), sheep (Juengel et al., 2002; Sawyer et al., 2002) and cattle (Burkhart et al., 2010; Hummitzsch et al., 2013). Moreover, in the bovine fetal ovary, the ovarian cortex forms lobes appearing to have slightly different developmental ages and giving rise to primordial follicles asynchronously within the same ovary (Burkhart et al., 2010; Garverick et al., 2010). In mouse, the primordial follicles were shown to consist of two classes that harbor a distinct development path. The medullary primordial follicles are synchronously activated after birth, forming the first wave of activated fast-growing follicles that may aid in the onset of puberty and provide mature oocytes up to 3 months of age. In contrast, the cortical primordial follicles are gradually activated, are slower growing and contribute to ovulation at later stages of the reproductive life (Zheng et al., 2014a). The existence of two populations of primordial follicles that exhibit distinct developmental dynamics and contribute differently to ovarian physiology is also suggested in primates (Zheng et al., 2014b). Their possible existence in sheep and cattle might explain the bi-phasic pattern of changes in ovarian follicle recruitment and growth observed in these species before puberty (Rawlings et al., 2003).

Recent evidence supports the existence of stem cells of a number of the different cell types within the ovary (Hummitzsch et al., 2015). Particularly, the isolation of oogonial stem cells from adult mouse and human ovaries has been reported; these cells exhibit both germ and stem cell markers in culture (White et al., 2012). When reintroduced into an ovarian somatic environment, the mouse oogonial stem cells have generated follicles capable of producing healthy offspring (Zou et al., 2009). However, the oogonial stem cells are unable to sustain by themselves the ovarian function into an advanced age, partly due to age-related changes in the ovarian microenvironment (Truman et al., 2017). Moreover, there are no data on their potential physiological role within the ovary, and specifically no evidence that they can contribute to the primordial follicle pool (Grieve et al., 2015). The dogma that a fixed pool of primordial follicles formed early in life serves as the only source of developing follicles throughout the reproductive lifespan still holds true (Lei and Spradling, 2013; Zhang et al., 2014).

\section{Molecular control}

During the last decades, the role of factors controlling the different phases of ovary and follicle formation has been deciphered, thanks to the generation of transgenic mice using gene knock out, knock in, targeted deletion, or over-expression strategies (Edson et al., 2009; Baillet and Mandon-Pépin, 2012; Monget et al., 2012; Pepling, 2012; Kerr et al., 2013; Findlay et al., 2015; Grive and Freiman, 2015). Mouse genetic models have identified numerous genes involved in PGC differentiation and migration, oogonia survival and proliferation, as well as in the initiation and execution of meiotic prophase in oocytes (Fig. 2). The mechanisms underlying these processes are generally well conserved from Drosophila to mice. The recently established transcriptome and DNA methylome landscapes of human migrating and gonadal PGCs were found in general similar to those of mouse PGCs at comparable stages (Guo et al., 2015). Owing to this high degree of conservation, factors shown to affect ovarian reserve establishment in mouse models are all potential candidates for identifying mutations associated with premature ovarian insufficiency in humans (Jagarlamudi et al., 2010; Pelosi et al., 2015), and with infertility in domestic animal species. However, despite conserved principles between species, some mechanistic differences exist between mice and a range of species including pigs, monkeys and humans, as exemplified for PGC specification at early developmental stages (Tang et al., 2016; Kobayashi et al., 2017). In this review, in addition to the knowledge acquired from mouse models, data from various species are presented and compared where possible.

As said above, primordial follicles are formed by germ cell cyst breakdown and assembly of individual oocytes with pre-granulosa cells. Intricate regulation of gene expression, including the oocyte-specific Figla (Soyal et al., 2000), Nobox (Lechowska et al., 2011) and Taf4b (Grive et al., 2014) transcription factors, is critical for these processes in mouse. The oocytespecific secreted factors BMP15 and GDF9, known to drive the growth of small follicles and the maturation of the cumulus-oocyte complex during folliculogenesis (Monniaux, 2016), might participate also in controlling follicle formation. Indeed, the formation of multi-oocyte follicles, indicative of the presence of defects in cyst breakdown and oocyte assembly with pre-granulosa cells, has been observed in Bmp15-/- Gdf9+/- mice (Yan et al., 2001). Moreover, it was recently reported that GDF9 and BMP15 can induce the formation of follicles from human embryonic stem cells expressing the germ cell-specific proteins DAZL and BOULE (Jung et al., 2017). However, the role of GDF9 and 
BMP15 in follicle formation in vivo remains speculative in humans and other species, particularly because BMP15 is not expressed until the follicle is actually formed and begins to grow. In the fetal sheep ovary, GDF9 expression starts at 56 days post-conception $(\mathrm{dpc})$ and is located in oocytes (Mandon-Pépin et al., 2003; Juengel et al., 2004). However, BMP15 expression is hardly detectable before $94 \mathrm{dpc}$, and in sheep homozygous for the $F e c X^{I}$ inactivating mutation in $B M P 15$, follicle formation seems normal (McNatty et al., 1995). Some observations suggest that BMPR1B, a BMP receptor known to bind BMP15/GDF9 heterodimers and BMP15 homodimers, may still participate in follicle formation in sheep. In the fetal sheep ovary, BMPR1B expression starts as soon as 25 $\mathrm{dpc}$, is high at the time of germline cyst breakdown (Mandon-Pépin et al., 2003) and is located in the mesonephric-derived cell streams and the ovigerous cords (Reader et al., 2012). In the ovaries of fetuses and newborn lambs homozygous for the $F e c B^{B}$ mutation in $B M P R 1 B$, the oocytes of the primordial follicles are larger and contain a greater volume of mitochondria, smooth endoplasmic reticulum and ribosomes, suggesting that the mutant form of BMPR1B has influenced the process of germline cyst breakdown and led to follicles better equipped for the initiation of follicular growth (Reader et al., 2012). The role of BMPR1B in the mechanisms of follicle formation and the BMP ligands able to activate BMPR1B signaling at this stage in the sheep ovary remain to be defined. Nevertheless, it can be speculated that BMP15 secreted by the first growing follicles may activate BMPR1B signaling in the ovigerous cords and influence the subsequent formation of follicles.

\section{Germ cell mitotic phase}

Germ cell meiotic phase

Meiotic arrest

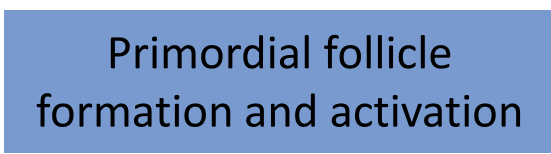

$\begin{array}{cc}\text { Cyst } & \text { Follicle } \\ \text { breakdown } & \text { activation }\end{array}$

\begin{tabular}{|c|c|c|c|}
\hline $\begin{array}{c}\text { PGC } \\
\text { specification }\end{array}$ & $\begin{array}{c}\text { Ovary } \\
\text { differentiation }\end{array}$ & $\begin{array}{c}\text { Oogonia } \\
\text { differentiation }\end{array}$ & $\begin{array}{l}\text { Meiotic } \\
\text { entry }\end{array}$ \\
\hline
\end{tabular}
and survival

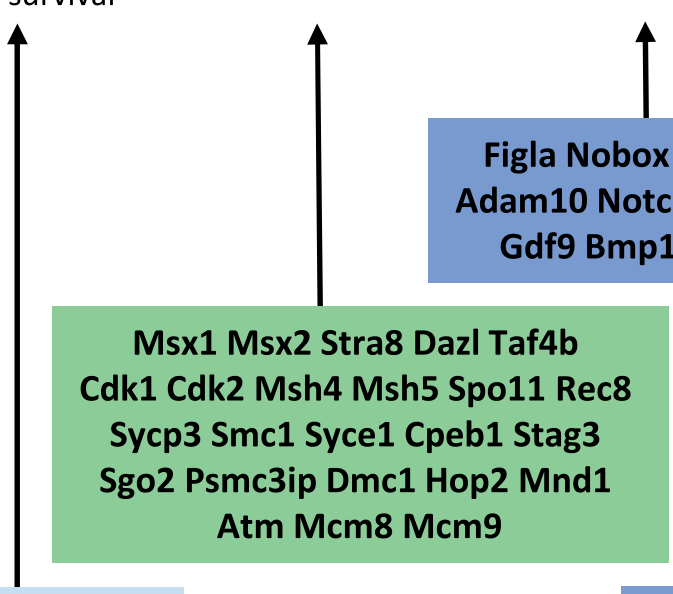

$$
\begin{aligned}
& \text { Nanos3 Tial1 Kitlg Kit } \\
& \text { Pou5f1 Zfx Pin1 Lats1 } \\
& \text { Fanca Fancc Fancg } \\
& \text { Bcl2 Bcl2/1 Bax Ahr Bbc3 }
\end{aligned}
$$
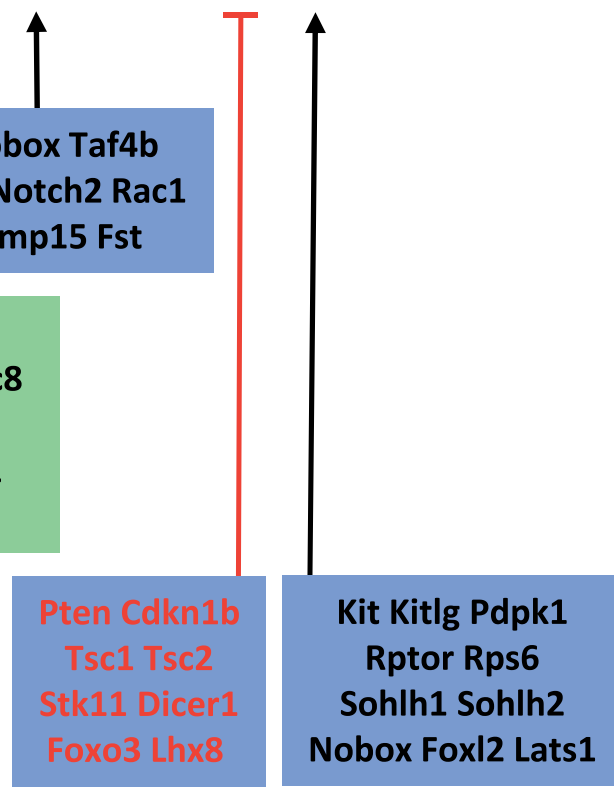

Figure 2. Genes with in vivo mutations affecting the different steps of primordial follicle formation and activation in mouse. Genetically modified mouse models exhibit phenotypes similar to those of premature ovarian insufficiency in humans. Black font: positive regulators, red font: negative regulators. From Edson et al., 2009; Jagarlamudi et al., 2010; Baillet and Mandon-Pépin, 2012; Monget et al., 2012; Pelosi et al., 2015.

In addition, some somatic cell-derived factors play important roles in cyst breakdown. Indeed, estradiol signaling is critical for inhibiting this process until birth in rodents (Chen et al., 2007) and may regulate it in ruminants as well (Fortune et al., 2010, 2013). In mouse, growth factors such as activin/follistatin and neurotrophins also influence cyst breakdown and the size of the primordial follicle pool
(Bristol-Gould et al., 2006; Kerr et al., 2009; Kimura et al., 2011), and recently the disintegrin Adam 10 has been shown to govern the recruitment of the pregranulosa cells in cysts (Feng et al., 2016). From data in mice, the actions of these various factors converge to modulate the Jagged/Notch signaling pathway in germ cell cysts. Particularly, the Notch2 gene encoding a Notch receptor in pre-granulosa cells orchestrates cyst 
breakdown, postnatal apoptosis of oocytes and primordial follicles assembly (Xu and Gridley, 2013) and the oocyte-specific secretory proteins Jagged1 (a Notch ligand), Gdf9 and Bmp15 activate the Notch signaling pathway in pre-granulosa cells (Zhao et al., 2016). All these observations highlight the importance of crosstalk between germ cells and pre-granulosa cells for the formation of primordial follicles.

The inactivation of genes controlling the processes of PGC specification and migration, ovary differentiation, meiosis initiation and execution of meiotic prophase leads generally to the absence of germ cells in the ovaries of mutant mice. Most inactivation of genes involved in the regulation of oogonia proliferation and survival, or germ cell cyst breakdown lead also to female infertility due to the absence of primordial follicles or a sharp reduction in their numbers at birth. However, in some cases, as in the inactivation of the pro-apoptotic factors $B a x$ and $B b c 3$, or the overexpression of the pro-survival factor $B c l 2$, the number of primordial follicles of the initial reserve is increased (Perez et al., 1999; Flaws et al., 2001; Myers et al., 2014). In mice over-expressing Bcl2 in ovaries, the surfeit of primordial follicles is not maintained in the long term, suggesting that the ovary may contain a sensing mechanism by which excess numbers of primordial follicles at birth are detected and removed from the ovary by adulthood (Flaws et al., 2001). The importance of postnatal regulations of the number of primordial follicles has also been shown in ewes carrying the $F_{e c B}{ }^{B}$ mutation in BMPRIB. The establishment of the ovarian reserve is delayed in mutant ewes (McNatty et al., 1995) and at birth their ovaries contain lower numbers of primordial follicles than wild-type ewes, but at 5 years of age mutant ewes are still fertile and their ovarian reserve is even higher, due to a lower rate of primordial follicle activation (Ruoss et al., 2009). These examples in mouse and sheep genetic models demonstrate that, in the presence of a mutation affecting moderately the establishment of the initial reserve of primordial follicles, the fertility and reproductive longevity of the female are not determined at birth. Similar compensatory postnatal mechanisms have been observed following the administration of activin to neonatal mice, since despite an increased number of primordial follicles in the mice ovaries after treatment, the excess follicles containing oocytes of poor quality is eliminated prior to puberty (Bristol-Gould et al., 2006).

\section{Environmental and hormonal control}

In sheep, as in cattle and humans, primordial follicles are formed before birth (Fig. 1) so that the establishment of the ovarian reserve is under the control of the maternal environment. All metabolic, hormonal or health changes in the maternal compartment and pollutants able to cross the placenta may affect the development of the fetal gonads. These maternal or external environmental factors can act directly on the developing ovary, but they impact also on various organs, particularly the hypothalamo-pituitary complex, the liver and the pancreas (Rhind et al., 2001;
Padmanabhan and Veiga-Lopez, 2013), as well as the adipose tissue, all able to affect indirectly ovarian function and fertility. Whether the environmental factors acting directly on follicle formation can also affect long-term fertility, and through which mechanisms, is a difficult question. This review will focus on the known effects of nutrition, steroids and some endocrine-disrupting factors on ovarian reserve establishment, and discuss their mechanisms of action and potential consequences for fertility.

\section{Nutritional factors}

Maternal nutritional status participates in programming growth, development, and function of the major fetal organ systems. Placental insufficiency impairs fetal development and reduces the number of primordial follicles in the ovaries of fetuses and neonates in humans (de Bruin et al., 1998) and sheep (Da Silva et al., 2003). Maternal overnutrition reduces also the number of primordial follicles in fetal bovine ovaries at the end of pregnancy, but concomitantly the number of growing follicles is increased, suggesting that the initiation of follicular growth has been activated (Weller et al., 2016). There is little information on the effects of maternal nutrition on the initial size of the pool of primordial follicles, but increasing evidence demonstrates that nutrition modulates the dynamics of ovarian reserve establishment in ruminant fetuses and rodent neonates, with functional consequences on follicular growth.

Undernutrition of ewes from the time of mating significantly retards ovarian development in fetal ovaries. Particularly, the ovaries of fetuses from feedrestricted ewes contain more germ cells entering the initial stages of meiosis at a time when a large proportion of them has completed this process (Borwick et al., 1997). This delay in meiosis onset is induced by the combination of maternal undernutrition before ovarian differentiation (days 0-30 of pregnancy) and during the phases of germ cell mitosis and meiosis entry (days 31-65 of pregnancy; Rae et al., 2001). Interestingly, undernutrition imposed during each of these gestational periods reduces also the incidence of follicle development beyond the primordial stages (Rae et al., 2001). These observations indicate the existence of a precocious window of ovarian sensitivity, during which nutritional disorders can affect the dynamics of follicle formation and compromise subsequent follicular development.

The mechanism of action of nutrients on follicle formation remains poorly understood. Female rats born to mothers fed a high-fat diet throughout pregnancy have fewer oocytes in fetal ovaries at embryonic day 20 and it was speculated that increased maternal-fetal inflammation associated with maternal obesity (Aye et al., 2014) may have contributed to accelerated fetal oocyte loss (Tsoulis et al., 2016). In a murine pharmacological model of maternal diabetes induced by streptozotocin administration, in utero exposure of mice to hyperglycemia decreases the expression of genes involved in meiosis initiation 
(Stra8, Dmc1 and Sycp3) and germ cell cyst breakdown (Nobox, Figla and Bmp15) and impairs the initiation of meiosis and follicle assembly in the fetal offspring ovaries (Qiu et al., 2017). The starvation of mouse pups between 1.5 and 3 days of postnatal life, when most primordial follicles are assembling, leads also to a decrease in the expression of Nobox and the impairment of germ cell cyst breakdown; in the ovaries of the starved pups, the alteration of metabolic parameters, exemplified by the lower expression of genes encoding proteins of fatty acid synthesis such as Fabp5, Cpt2 and Acsl3, could have triggered an oxidative stress responsible for the increased autophagy and apoptosis observed in the oocytes within cysts and in the primordial follicles (Wang et al., 2017).

Besides a possible direct effect of glucose and other nutrients on ovarian development, metabolic hormones can regulate follicle formation. Insulin accelerates primordial follicle assembly in rodent ovaries and increases apoptosis in germ cell cysts in vitro, as shown in hamster ( $\mathrm{Yu}$ and Roy, 1999) and mouse (Feng et al., 2015). Leptin, a major adipokine able to modulate lipid and glucose metabolism and insulin sensitivity, could also regulate follicle formation. Indeed, in the ovaries of piglets containing a substantial proportion of germ cells not yet enclosed in follicles but grouped into germ cell cysts, leptin receptors are present on oogonia and oocytes (Fig. 3). These germ cells were found to express six different isoforms of leptin receptors, potentially able to activate the MAP kinases and PI3/AKT pathways (Attig et al., 2013). Moreover, postnatal leptin treatment of piglets with intra-uterine growth retardation accelerates follicle formation and activation, since the ovaries of leptin-treated piglets contain lower percentages of oogonia and oocytes in meiotic prophase, but higher percentages of oocytes in the dictyate stage within germ cell cysts, primordial and primary follicles (Attig et al., 2013).
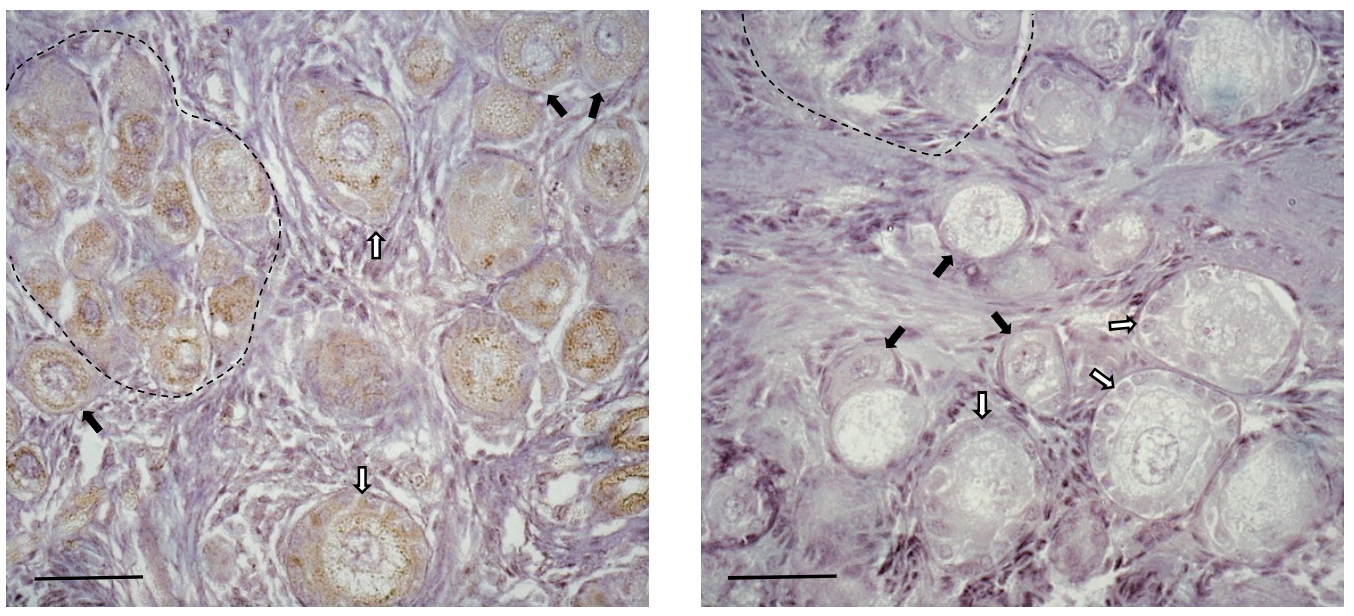

Figure 3. Expression of leptin receptors in the ovaries of 21 days-old piglets. For immunostaining, ovarian sections were incubated with leptin receptor antibody (Ob-R (M-18)-R, sc-1834-R; Santa Cruz Biotechnology Inc, Heidelberg, Germany; dilution 1/250), without (A) and with (B) displacement by the peptide used as immunogen for antibody preparation. Leptin receptors are detectable in all germ cells and some granulosa cells of primary follicles. Dotted lines delineate germ cell cysts. Primordial and primary follicles are indicated by black and open arrows, respectively. Bar $=50 \mu \mathrm{m}$. (Monniaux and Brisard, 2018; INRA, Nouzilly, France; unpublished pictures).

Whether the early-life nutritional environment affects fertility and reproductive longevity of mammals is a controversial issue (Gardner et al., 2009; Sloboda et al., 2011). After induction of maternal diabetes by streptozotocin in mouse, the reproductive performance of the offspring is severely decreased in the long term, but their postnatal growth and physical development are also impaired or delayed, indicating the establishment of a sustainable metabolic syndrome (Spadotto et al., 2012). In sheep, inadequate maternal nutrition has little effect, if any, on puberty and ovulation rate of the offspring when postnatal growth is normal (Da Silva et al., 2001; Rae et al., 2002). None of the studies of maternal undernutrition, overfeeding or high-fat diet during the period of establishment of the ovarian reserve of their offspring have demonstrated that the fertility or reproductive longevity of the offspring is affected in the absence of metabolic syndrome.

Some changes in germ cell numbers induced by undernutrition or overfeeding in the early phases of ovarian development are compensated in offspring at birth or after a period of normal feeding. For instance, in rats born to mothers fed a high-fat diet throughout pregnancy and lactation, despite a significant decrease in oocyte number during late fetal life, neonates at day 4 of postnatal life demonstrate higher numbers of primordial follicles than control offspring, suggesting that a recovery mechanism has occurred during follicle formation (Tsoulis et al., 2016). Also, following a reduced rate of germ cell cyst breakdown induced by the starvation of mouse pups in early postnatal life, the animals recover a normal number of primordial follicles in their ovaries after 3 weeks from re-feeding (Wang et al., 2017). Despite the existence of compensation mechanisms in developmental processes, the early-life nutritional environment before or/and during primordial follicle formation leaves an imprint since it modulates the long-term ability of follicles to enter growth and 
develop. Indeed, neonatal overfeeding of rats induces the accelerated activation of primordial follicles before puberty and at adulthood (Sominsky et al., 2016). Moreover, maternal high-fat diet induces follicular atresia in the ovaries of rabbit and rat offspring in adulthood (Leveillé et al., 2014; Tsoulis et al., 2016). Interestingly, in the rat model, antral follicles of adult offspring exhibit reduced $\mathrm{FSH}$ responsiveness and express low levels of the estrogen receptor Esrl and the oocyte secreted factor Gdf9 (Tsoulis et al., 2016), both factors well known to regulate follicular development and FSH sensitivity. Furthermore, undernutrition of rats during pregnancy decreases the number of antral growing follicles in the ovaries of adult offspring (Bernal et al., 2010). In a similar way, offspring from cows nutritionally restricted during their first trimester of gestation (before the full establishment of the ovarian reserve in offspring) exhibit, from birth to the adult age, lower numbers of antral follicles than control offspring from non-restricted mothers (Sullivan et al., 2009; Mossa et al., 2013). This difference in folliculogenesis activity between offspring from restricted and nonrestricted cows cannot be attributed to metabolic differences since offspring have similar birth weights and postnatal growth rates (Mossa et al., 2013). Cows with low numbers of antral follicles on their ovaries are known to have numerous phenotypic characteristics usually associated with subfertility (Ireland et al., 2011), but whether alterations in folliculogenesis of the offspring after precocious maternal nutritional restriction may, in turn, impact on their fertility and reproductive longevity has not been assessed in this bovine model.

\section{Steroids and endocrine-disrupting factors}

In cattle and sheep, fetal ovarian capacity to produce steroids is high before follicle formation begins and decreases around the time follicles first appear (Quirke et al., 2001; Yang and Fortune, 2008; Fig. 1). In mice, fetal ovaries have also a significant steroidogenic activity, which drops before cyst breakdown; in addition, they are exposed to high levels of maternal steroids, which fall dramatically after birth (Dutta et al., 2014). From these observations, the hypothesis that steroids may inhibit follicle formation was tested in vitro on postnatal rodent ovaries and fetal bovine ovaries. In rat (Kezele and Skinner, 2003), mouse (Chen et al., 2007) and cattle ovaries (Nilsson and Skinner, 2009), progesterone inhibits follicle formation, whereas the non-aromatizable androgen 5alphadihydrotestosterone does not in cattle ovaries (Fortune et al., 2010). Estradiol at high concentrations impairs primordial follicle formation in mice and cattle (Chen et al., 2007; Fortune et al., 2010) but not in rats, whereas conversely low concentrations of estradiol stimulate primordial follicle formation in vivo and in vitro in hamster ovaries (Wang and Roy, 2007). In vivo, the number of primordial follicles is reduced by $50 \%$ in the ovaries of near-term fetal baboons deprived of estrogen by administration of an aromatase inhibitor in utero, and restored to normal in animals supplemented with estrogen (Zachos et al., 2002). Moreover, fetuses of sheep androgenized in utero from day 30 of pregnancy have, at day 90 , nearly double the proportion of germ cells enclosed in follicles compared with control animals (Comim et al., 2015), indicating that follicle formation is accelerated by testosterone or by estrogenic action stemming from aromatization of testosterone to estradiol. Altogether, these observations indicate that each steroid acts upon follicle formation in a complex species-specific and dose-dependent fashion.

In sheep, the receptors of estrogens (ESR1 and ESR2), androgens (AR), as well as progesterone (PGR), are all expressed in the surface epithelium and ovarian stroma of the fetal ovaries (Juengel et al., 2006). In cattle, ESR1 is mostly found in the surface epithelium whereas ESR2 is expressed in the medulla, germ cells and pre-granulosa cells during early fetal life, then both receptors seem to be expressed in all cell types after 110 dpc (Burkhart et al., 2010; Garverick et al., 2010). In humans, ESR2 is localized primarily to germ cells, but AR expression is confined to somatic cells between clusters of germ cells (Fowler et al., 2011). The potential exists therefore that all steroids could interfere with somatic-to-germ cell signaling during follicle formation, but it needs exploring. Interestingly, estrogen receptors, particularly ESR2, are expressed in all types of germ cells and in pre-granulosa cells in sheep, cattle and humans, suggesting that both direct and indirect actions of estrogens are possible on germ cells during follicle formation. From the data available, estrogens could control follicle formation through intra-ovarian mechanisms involving members of the TGF-beta family. Indeed, estrogens regulate the formation of primordial follicles in baboons by controlling the intraovarian inhibin/activin ratio (Billiar et al., 2003) and recently, BMP2 has been shown to mediate the effect of estrogens on follicle formation in the hamster ovary, since the interference of BMP2 production or its receptor function disrupts estradiol-stimulated primordial follicle formation (Chakraborty and Roy, 2017). However, the mechanism by which low and high concentrations of estrogens exert opposite effects on follicle formation are not yet understood.

Increasing evidence indicate that environmental factors with estrogen-like activity modulate importantly follicle formation. Mice treated neonatally with genistein, the primary soy phytoestrogen, have multi-oocyte follicles in ovaries; genistein was found to inhibit germ cell cyst breakdown and attenuate oocyte cell death, and these effects are mediated by the estrogen receptor Esr2 (Jefferson et al., 2006). Similar effects were observed after exposure of neonatal mice to synthetic estrogens, such as diethylstilbestrol, ethinylestradiol and bisphenol A (Karavan and Pepling, 2012). Oral administration of zearalenone (a mycoestrogen produced by Fusarium graminearum) to pregnant mice impairs germ cell meiotic progression, decreases the expression of the meiosis-specific genes Dazl, Stra8, Scp1 and Scp3, increases DNA double-strand breaks at the diplotene stage and affects primordial follicle assembly in the fetal ovaries (Liu et al., 2017). In a similar way, 
following exposure of pregnant mice to diethylhexylphthalate (DEHP), a widespread plasticizer with estrogen-like activity, the first meiotic progression of female fetal germ cells is delayed, associated with an increase in DNA methylation level of Stras and a decrease in its expression levels (Zhang et al., 2015). In neonatal mice, DEHP impairs also primordial follicle assembly, while decreasing the gene and protein expression of Esr2 and components of Notch signaling in mouse ovaries (Mu et al., 2015). In sheep, exposure (by grazing pastures fertilized with sewage sludge) of pregnant ewes to a real-life mixture of environmental chemicals with pro-estrogenic actions disrupts fetal ovarian development and alters the fetal ovarian transcriptome and proteome at day 110 of pregnancy (Fowler et al., 2008).

Estradiol is not required for the initiation of follicle growth in mice (Britt et al., 2000) but aromatase knockout mice have reduced numbers of primordial and primary follicles compared with wild-type mice at 10 weeks of age (Britt et al., 2004). The primordial follicles that form in ovaries of estrogen-deprived baboon fetuses contain oocytes with a marked reduction in microvilli, structures essential for uptake of substrates from surrounding granulosa cells and presumably longterm follicle survival (Zachos et al., 2004). However, lowering estrogen levels during the period of follicle formation does not impair folliculogenesis and ovulation at adulthood in baboons (Pepe et al., 2013).

Steroid excess during follicle formation can be deleterious for subsequent follicular development. The exposure of ewes between 60 and 80 days of pregnancy to a mixture of environmental chemicals with estrogenlike activity decreases primordial follicle activation in fetal ovaries near term and increases atresia rate in activated follicles (Bellingham et al., 2013; Lea et al., 2016). In contrast, prenatal testosterone excess between days 30 and 90 of pregnancy enhances the activation of primordial follicles and early follicular development in fetal and postnatal sheep ovaries (Steckler et al., 2005; Smith et al., 2009). In sheep, fetal exposure to excess testosterone was shown to disrupt the ovarian proliferation/apoptosis balance, with a decrease in BAX expression in the primordial and primary follicles of fetuses appearing to be programmed by androgenic actions, and changes in PCNA, BCL2, and CASP3 expression in the growing follicles of adults programmed by estrogenic actions of testosterone (Salvetti et al., 2012). This prenatal treatment by testosterone leads to early reproductive failure in adult ewes (Clarke et al., 1977; Birch et al., 2003), resulting from the combination of neuroendocrine, metabolic and ovarian defects (Padmanabhan and Veiga-Lopez, 2013) and similar conclusions were drawn from rodent models of early exposure to steroids (Zambrano et al., 2014).

Early exposure to environmental factors with estrogen-like activity affects long-term primordial follicle activation and the observed effects are transgenerational. For instance, maternal DEHP exposure significantly accelerates the recruitment of primordial follicles in the F1 and F2 generations of mice (Zhang et al., 2015). The modification of the DNA methylation of imprinted genes in F1 mouse oocytes induced by maternal DEHP exposure is heritable to F2 offspring (Li et al., 2014). Recently, it was shown that the reduction of the ovarian follicular reserve and of the oocyte developmental capacity induced by maternal DEHP exposure is transmitted through the female germline up to the third generation (Pocar et al., 2017).

\section{Conclusions}

During the last decades, our knowledge of the cellular mechanisms and the molecular and environmental control of the establishment of the ovarian reserve of the primordial follicles has made significant progress. Some of the intra-ovarian mechanisms currently known to control germ cell cyst breakdown and primordial follicle assembly are illustrated in Fig. 4. Inadequate maternal nutrition, exposure to steroid excess or to environmental pollutants with estrogen-like activity at the time of follicle formation can delay or modulate the mechanisms controlling the establishment of the ovarian reserve, leading to the formation of a decreased number of primordial follicles in the fetal or neonatal ovaries.

The size of the initial follicular reserve is primarily dependent on genetic determinants, and mutations affecting factors controlling the different steps of ovarian reserve establishment can lead to the absence of primordial follicles, or a sharp reduction in their numbers, incompatible with fertility in the adult. However, having two- or three-fold more or less follicles than the mean number characteristic of the species at birth is not a determinant for fertility and reproductive longevity in adulthood, as demonstrated in mice (Flaws et al., 2001) and sheep (Ruoss et al., 2009). Rather, the dynamics of follicle consumption from the initial primordial follicle pool determine the female reproductive lifespan (Monniaux et al., 2014).

From the data available, the ovarian changes induced by environmental factors present during the fetal or neonatal life do not seem to alter the fertility of young females, unless their metabolism or neuroendocrine status is affected, but their consequences on the reproductive lifespan have not yet been established. To understand the impact of the early-life environment on fertility of both young and older adults, there is now a significant need to consider the different types of populations of primordial follicles, which have distinct developmental dynamics and contribute differently to ovarian functionality (Zheng et al., 2014b).

The early-life ovarian environment modulates in the long term the rate of primordial activation and the dynamics of the small growing follicles in adult ovaries. As these processes are little or not influenced by the gonadotropins, the observed changes result likely from direct imprinting effects of environmental factors on the germ and/or somatic ovarian cells, occurring before and during follicle formation. Increasing evidence indicate that environmental chemicals with estrogen-like activity leave epigenetic marks on the germ cells, and their effects are transmitted through the female germline up to the third generation in mice (Pocar et al., 2017). 
Further investigations are needed now to decipher the underlying mechanisms of these epigenetic effects and understand the long-term consequences of gene imprinting on the size and quality of the ovarian reserve.

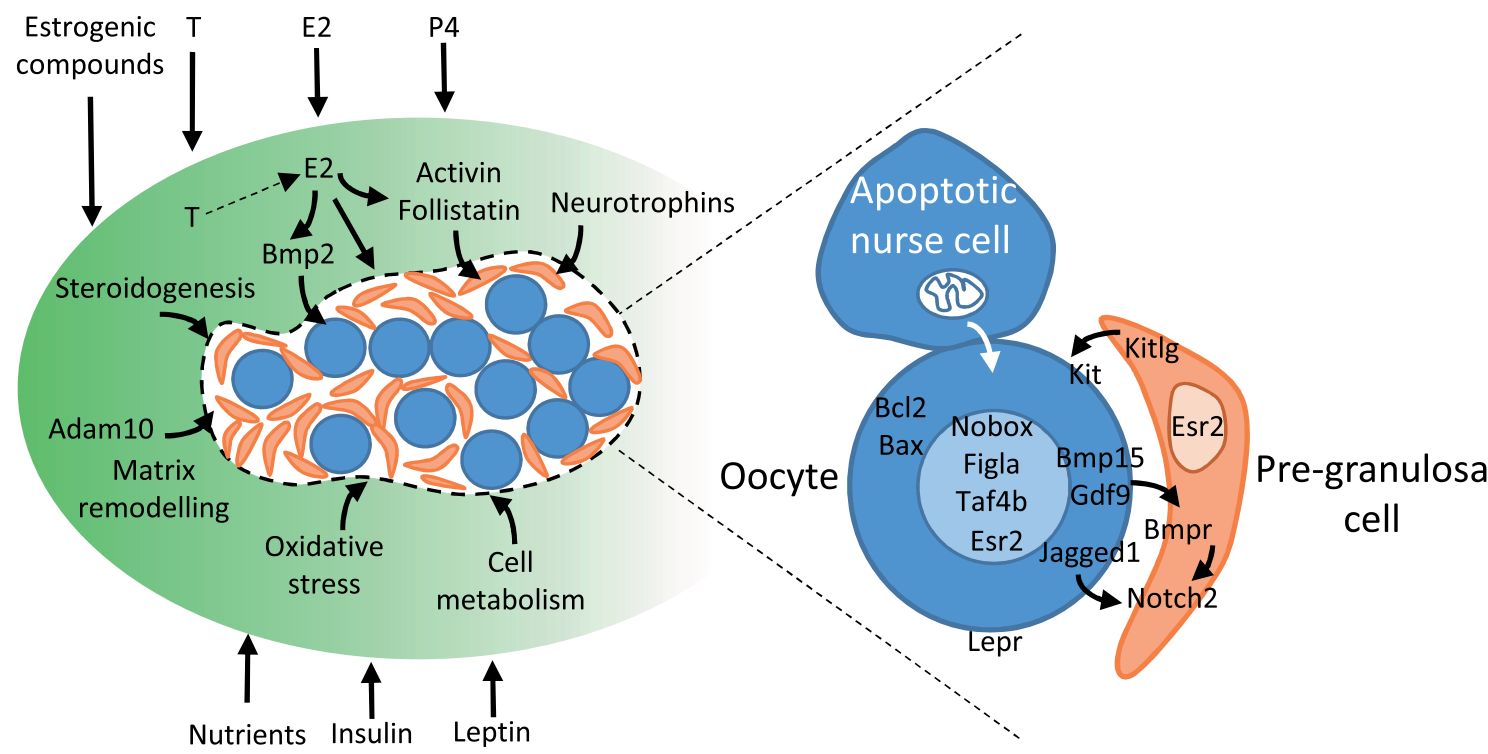

Figure 4. Schematic representation of some mechanisms currently known to regulate germ cell cyst breakdown and follicle assembly. A germ cell cyst is represented (delineated by a dotted line), containing oocytes (blue round cells) and pre-granulosa cells (small pink cells). The intra-ovarian mechanisms regulating germ cell cyst breakdown and the environmental factors currently known to modulate them are indicated in the left part of the figure. Some known interactions between germ and somatic cells, and between germ cells themselves, are zoomed in the right part of the figure.

\section{References}

Attig L, Brisard D, Larcher T, Mickiewicz M, Guilloteau P, Boukthir S, Niamba CN, Gertler A, Djiane J, Monniaux D, Abdennebi-Najar L. 2013. Postnatal leptin promotes organ maturation and development in IUGR piglets. PLoS One, 8:e64616. doi.org/10.1371/journal.pone.0064616.

Aye IL, Lager S, Ramirez VI, Gaccioli F, Dudley DJ, Jansson T, Powell TL. 2014. Increasing maternal body mass index is associated with systemic inflammation in the mother and the activation of distinct placental inflammatory pathways. Biol Reprod, 90:129. doi: 10.1095/biolreprod.113.116186.

Baillet A, Mandon-Pépin B. 2012. Mammalian ovary differentiation - a focus on female meiosis. Mol Cell Endocrinol, 356:13-23.

Baker TG. 1963. A quantitative and cytological study of germ cells in human ovaries. Proc R Soc Lond B Biol Sci, 158:417-433.

Bellingham M, Amezaga MR, Mandon-Pépin B, Speers CJ, Kyle CE, Evans NP, Sharpe RM, Cotinot C, Rhind SM, Fowler PA. 2013. Exposure to chemical cocktails before or after conception--- the effect of timing on ovarian development. Mol Cell Endocrinol, 376:156-172.

Bernal AB, Vickers MH, Hampton MB, Poynton RA, Sloboda DM. 2010. Maternal undernutrition significantly impacts ovarian follicle number and increases ovarian oxidative stress in adult rat offspring. PLoS One, 5:e15558. doi.org/10.1371/journal.pone.0015558.

Billiar RB, Zachos NC, Burch MG, Albrecht ED,
Pepe GJ. 2003. Up-regulation of alpha-inhibin expression in the fetal ovary of estrogen-suppressed baboons is associated with impaired fetal ovarian folliculogenesis. Biol Reprod, 68:1989-1996.

Birch RA, Padmanabhan V, Foster DL, Unsworth WP, Robinson JE. 2003. Prenatal programming of reproductive neuroendocrine function: fetal androgen exposure produces progressive disruption of reproductive cycles in sheep. Endocrinology, 144:14261434.

Black JL, Erickson BH. 1968. Oogenesis and ovarian development in the prenatal pig. Anat Rec, 161: 45-55.

Block E. 1952. Quantitative morphological investigations of the follicular system in women; variations at different ages. Acta Anat (Basel), 14:108123.

Borwick SC, Rhind SM, McMillen SR, Racey PA. 1997. Effect of undernutrition of ewes from the time of mating on fetal ovarian development in mid gestation. Reprod Fertil Dev, 9:711-715.

Bristol-Gould SK, Kreeger PK, Selkirk CG, Kilen SM, Cook RW, Kipp JL, Shea LD, Mayo KE, Woodruff TK. 2006. Postnatal regulation of germ cells by activin: the establishment of the initial follicle pool. Dev Biol, 298:132-148.

Britt KL, Drummond AE, Cox VA, Dyson M, Wreford NG, Jones ME, Simpson ER, Findlay JK. 2000. An age-related ovarian phenotype in mice with targeted disruption of the Cyp 19 (aromatase) gene. Endocrinology, 141:2614-2623.

Britt KL, Saunders PK, McPherson SJ, Misso ML, Simpson ER, Findlay JK. 2004. Estrogen actions on follicle formation and early follicle development. Biol 
Reprod, 71:1712-1723.

Burkhart MN, Juengel JL, Smith PR, Heath DA, Perry GA, Smith MF, Garverick HA. 2010. Morphological development and characterization of aromatase and estrogen receptors alpha and beta in fetal ovaries of cattle from days 110 to 250. Anim Reprod Sci, 117:43-54.

Chakraborty P, Roy SK. 2017. Stimulation of primordial follicle assembly by estradiol-17beta requires the action of bone morphogenetic protein-2 (BMP2). Sci Rep, 7:15581. doi:10.1038/s41598-01715833-4.

Chen Y, Jefferson WN, Newbold RR, Padilla-Banks E, Pepling ME. 2007. Estradiol, progesterone, and genistein inhibit oocyte nest breakdown and primordial follicle assembly in the neonatal mouse ovary in vitro and in vivo. Endocrinology, 148:3580-3590.

Clarke IJ, Scaramuzzi RJ, Short RV. 1977. Ovulation in prenatally androgenized ewes. J Endocrinol, 73:385389.

Comim FV, Hardy K, Robinson J, Franks S. 2015. Disorders of follicle development and steroidogenesis in ovaries of androgenised foetal sheep. J Endocrinol, 225:39-46.

Da Silva P, Aitken RP, Rhind SM, Racey PA, Wallace JM. 2001. Influence of placentally mediated fetal growth restriction on the onset of puberty in male and female lambs. Reproduction, 122:375-383.

Da Silva P, Aitken RP, Rhind SM, Racey PA, Wallace JM. 2003. Effect of maternal overnutrition during pregnancy on pituitary gonadotrophin gene expression and gonadal morphology in female and male foetal sheep at day 103 of gestation. Placenta, 24:248257

de Bruin JP, Dorland M, Bruinse HW, Spliet W, Nikkels PG, Te Velde ER. 1998. Fetal growth retardation as a cause of impaired ovarian development. Early Hum Dev, 51:39-46.

Dutta S, Mark-Kappeler CJ, Hoyer PB, Pepling ME. 2014. The steroid hormone environment during primordial follicle formation in perinatal mouse ovaries Biol Reprod, 91:68. doi 10.1095/biolreprod.114.119214.

Edson MA, Nagaraja AK, Matzuk MM. 2009. The mammalian ovary from genesis to revelation. Endocr Rev, 30:624-712

Erickson BH. 1966. Development and radio-response of the prenatal bovine ovary. J Reprod Fertil, 10:97105 .

Feng L, Wang Y, Cai H, Sun G, Niu W, Xin Q, Tang $\mathbf{X}$, Zhang J, Wang C, Zhang H, Xia G. 2016. ADAM10-Notch signaling governs the recruitment of ovarian pregranulosa cells and controls folliculogenesis in mice. J Cell Sci, 129:2202-2212.

Feng XL, Sun YC, Zhang M, Cheng SF, Feng YN, Liu JC, Wang HH, Li L, Qin GQ, Shen W. 2015 Insulin regulates primordial-follicle assembly in vitro by affecting germ-cell apoptosis and elevating oestrogen. Reprod Fertil Dev, 27:1197-1204.

Findlay JK, Hutt KJ, Hickey M, Anderson RA. 2015. How is the number of primordial follicles in the ovarian reserve established? Biol Reprod, 93:111. doi: 10.1095/ biolreprod.115.133652.

Flaws JA, Hirshfield AN, Hewitt JA, Babus JK, Furth PA. 2001. Effect of bcl-2 on the primordial follicle endowment in the mouse ovary. Biol Reprod, 64:1153-1159.

Forabosco A, Sforza C. 2007. Establishment of ovarian reserve: a quantitative morphometric study of the developing human ovary. Fertil Steril, 88:675-683.

Fortune JE, Yang MY, Muruvi W. 2010. The earliest stages of follicular development: follicle formation and activation. Soc Reprod Fertil Suppl, 67:203-216.

Fortune JE, Yang MY, Allen JJ, Herrick SL. 2013. Triennial Reproduction Symposium: the ovarian follicular reserve in cattle: what regulates its formation and size? J Anim Sci, 91:3041-3050.

Fowler PA, Dora NJ, McFerran H, Amezaga MR, Miller DW, Lea RG, Cash P, McNeilly AS, Evans NP, Cotinot C, Sharpe RM, Rhind SM. 2008. In utero exposure to low doses of environmental pollutants disrupts fetal ovarian development in sheep. Mol Hum Reprod, 14:269-280.

Fowler PA, Anderson RA, Saunders PT, Kinnell H, Mason JI, Evans DB, Bhattacharya S, Flannigan S, Franks S, Monteiro A, O'Shaughnessy PJ. 2011. Development of steroid signaling pathways during primordial follicle formation in the human fetal ovary. $J$ Clin Endocrinol Metab, 96:1754-162.

Gardner DS, Ozanne SE, Sinclair KD. 2009. Effect of the early-life nutritional environment on fecundity and fertility of mammals. Philos Trans $R$ Soc Lond B Biol Sci, 364:3419-3427.

Garverick HA, Juengel JL, Smith P, Heath DA, Burkhart MN, Perry GA, Smith MF, McNatty KP. 2010. Development of the ovary and ontongeny of mRNA and protein for P450 aromatase (arom) and estrogen receptors (ER) alpha and beta during early fetal life in cattle. Anim Reprod Sci, 117:24-33.

Grieve KM, McLaughlin M, Dunlop CE, Telfer EE, Anderson RA. 2015. The controversial existence and functional potential of oogonial stem cells. Maturitas, 82:278-281.

Grive KJ, Seymour KA, Mehta R, Freiman RN. 2014. TAF4b promotes mouse primordial follicle assembly and oocyte survival. Dev Biol, 392:42-51.

Grive KJ, Freiman RN. 2015. The developmental origins of the mammalian ovarian reserve. Development, 142:2554-2563.

Guo F, Yan L, Guo H, Li L, Hu B, Zhao Y, Yong J, Hu Y, Wang X, Wei Y, Wang W, Li R, Yan J, Zhi X, Zhang Y, Jin H, Zhang W, Hou Y, Zhu P, Li J, Zhang L, Liu S, Ren Y, Zhu X, Wen L, Gao YQ, Tang F, Qiao J. 2015. The transcriptome and DNA methylome landscapes of human primordial germ cells. Cell, 161:1437-1452.

Hirshfield AN. 1992. Heterogeneity of cell populations that contribute to the formation of primordial follicles in rats. Biol Reprod, 47:466-472.

Hummitzsch K, Irving-Rodgers HF, Hatzirodos N, Bonner W, Sabatier L, Reinhardt DP, Sado Y, Ninomiya Y, Wilhelm D, Rodgers RJ. 2013. A new model of development of the mammalian ovary and 
follicles. PLoS One, 8:e55578. doi.org/10.1371/ journal.pone.0055578.

Hummitzsch K, Anderson RA, Wilhelm D, Wu J, Telfer EE, Russell DL, Robertson SA, Rodgers RJ. 2015. Stem cells, progenitor cells, and lineage decisions in the ovary. Endocr Rev, 36:65-91

Ireland JJ, Smith GW, Scheetz D, Jimenez-Krassel F, Folger JK, Ireland JL, Mossa F, Lonergan P, Evans AC. 2011. Does size matter in females? An overview of the impact of the high variation in the ovarian reserve on ovarian function and fertility, utility of anti-Mullerian hormone as a diagnostic marker for fertility and causes of variation in the ovarian reserve in cattle. Reprod Fertil Dev, 23:1-14. doi: 10.1071/RD10226.

Jagarlamudi K, Reddy P, Adhikari D, Liu K. 2010. Genetically modified mouse models for premature ovarian failure (POF). Mol Cell Endocrinol, 315:1-10. doi: 10.1016/j.mce.2009.07.016.

Jefferson W, Newbold R, Padilla-Banks E, Pepling M. 2006. Neonatal genistein treatment alters ovarian differentiation in the mouse: inhibition of oocyte nest breakdown and increased oocyte survival. Biol Reprod, 74:161-168.

Juengel JL, Sawyer HR, Smith PR, Quirke LD, Heath DA, Lun S, Wakefield SJ, McNatty KP. 2002. Origins of follicular cells and ontogeny of steroidogenesis in ovine fetal ovaries. Mol Cell Endocrinol, 191:1-10.

Juengel JL, Bodensteiner KJ, Heath DA, Hudson NL, Moeller CL, Smith P, Galloway SM, Davis GH, Sawyer HR, McNatty KP. 2004. Physiology of GDF9 and BMP15 signalling molecules. Anim Reprod Sci, 82/83:447-460.

Juengel JL, Heath DA, Quirke LD, McNatty KP. 2006. Oestrogen receptor alpha and beta, androgen receptor and progesterone receptor mRNA and protein localisation within the developing ovary and in small growing follicles of sheep. Reproduction, 131:81-92.

Jung D, Xiong J, Ye M, Qin X, Li L, Cheng S, Luo M, Peng J, Dong J, Tang F, Shen W, Matzuk MM, Kee K. 2017. In vitro differentiation of human embryonic stem cells into ovarian follicle-like cells. Nat Commun, 8:15680. doi: 10.1038/ncomms 15680.

Karavan JR, Pepling ME. 2012. Effects of estrogenic compounds on neonatal oocyte development. Reprod Toxicol, 34:51-56.

Kerr B, Garcia-Rudaz C, Dorfman M, Paredes A, Ojeda SR. 2009. NTRK1 and NTRK2 receptors facilitate follicle assembly and early follicular development in the mouse ovary. Reproduction, 138:131-40.

Kerr JB, Myers M, Anderson RA. 2013. The dynamics of the primordial follicle reserve. Reproduction, 146:R205-215.

Kezele P, Skinner MK. 2003. Regulation of ovarian primordial follicle assembly and development by estrogen and progesterone: endocrine model of follicle assembly. Endocrinology, 144:3329-3337.

Kimura F, Bonomi LM, Schneyer AL. 2011. Follistatin regulates germ cell nest breakdown and primordial follicle formation. Endocrinology, 152:697-
706.

Kobayashi T, Zhang H, Tang WWC, Irie N, Withey S, Klisch D, Sybirna A, Dietmann S, Contreras DA, Webb R, Allegrucci C, Alberio R, Surani MA. 2017. Principles of early human development and germ cell program from conserved model systems. Nature, 546:416-420.

Konishi I, Fujii S, Okamura H, Parmley T, Mori T. 1986. Development of interstitial cells and ovigerous cords in the human fetal ovary: an ultrastructural study. $J$ Anat, 148:121-135.

Lea RG, Amezaga MR, Loup B, Mandon-Pépin B, Stefansdottir A, Filis P, Kyle C, Zhang Z, Allen C, Purdie L, Jouneau L, Cotinot C, Rhind SM, Sinclair KD, Fowler PA. 2016. The fetal ovary exhibits temporal sensitivity to a 'real-life' mixture of environmental chemicals. Sci Rep, 6:22279. doi:10.1038/srep22279.

Lechowska A, Bilinski S, Choi Y, Shin Y, Kloc M, Rajkovic A. 2011. Premature ovarian failure in noboxdeficient mice is caused by defects in somatic cell invasion and germ cell cyst breakdown. $J$ Assist Reprod Genet, 28:583-589.

Lei L, Spradling AC. 2013. Female mice lack adult germ-line stem cells but sustain oogenesis using stable primordial follicles. Proc Natl Acad Sci USA, 110:85858590.

Lei L, Spradling AC. 2016. Mouse oocytes differentiate through organelle enrichment from sister cyst germ cells. Science, 352:95-99.

Leveillé P, Tarrade A, Dupont C, Larcher T, Dahirel M, Poumerol E, Cordier AG, Picone O, MandonPépin B, Jolivet G, Levy R, Chavatte-Palmer $\mathbf{P}$. 2014. Maternal high-fat diet induces follicular atresia but does not affect fertility in adult rabbit offspring. $J$ Dev Orig Health Dis, 5:88-97.

Li L, Zhang T, Qin XS, Ge W, Ma HG, Sun LL, Hou ZM, Chen H, Chen P, Qin GQ, Shen W, Zhang XF. 2014. Exposure to diethylhexyl phthalate (DEHP) results in a heritable modification of imprint genes DNA methylation in mouse oocytes. Mol Biol Rep, 41:12271235.

Liu KH, Sun XF, Feng YZ, Cheng SF, Li B, Li YP, Shen W, Li L. 2017. The impact of Zearalenone on the meiotic progression and primordial follicle assembly during early oogenesis. Toxicol Appl Pharmacol, 329:917.

Mandon-Pépin B, Oustry-Vaiman A, Vigier B, Piumi F, Cribiu E, Cotinot C. 2003. Expression profiles and chromosomal localization of genes controlling meiosis and follicular development in the sheep ovary. Biol Reprod, 68:985-995.

McNatty KP, Smith P, Hudson NL, Heath DA, Tisdall DJ, O WS, Braw-Tal R. 1995. Development of the sheep ovary during fetal and early neonatal life and the effect of fecundity genes. J Reprod Fertil Suppl, 49:123-135.

McNatty KP, Fidler AE, Juengel JL, Quirke LD, Smith PR, Heath DA, Lundy T, O'Connell A, Tisdall DJ. 2000. Growth and paracrine factors regulating follicular formation and cellular function. Mol Cell Endocrinol, 163:11-20. 
Monget P, Bobe J, Gougeon A, Fabre S, Monniaux D, Dalbies-Tran R. 2012. The ovarian reserve in mammals: a functional and evolutionary perspective. Mol Cell Endocrinol, 356:2-12.

Monniaux D, Clément F, Dalbies-Tran R, Estienne A, Fabre S, Mansanet C, Monget P. 2014. The ovarian reserve of primordial follicles and the dynamic reserve of antral growing follicles: what is the link? Biol Reprod, 90:85. doi: 10.1095/biolreprod.113.117077.

Monniaux D. 2016. Driving folliculogenesis by the oocyte-somatic cell dialog: lessons from genetic models. Theriogenology, 86:41-53.

Mork L, Maatouk DM, McMahon JA, Guo JJ, Zhang P, McMahon AP, Capel B. 2012. Temporal differences in granulosa cell specification in the ovary reflect distinct follicle fates in mice. Biol Reprod, 86:37. doi: 10.1095/biolreprod.111.095208.

Mossa F, Carter F, Walsh SW, Kenny DA, Smith GW, Ireland JL, Hildebrandt TB, Lonergan $P$, Ireland JJ, Evans AC. 2013. Maternal undernutrition in cows impairs ovarian and cardiovascular systems in their offspring. Biol Reprod, 88:92. doi: 10.1095/biolreprod.112.107235.

Mu X, Liao X, Chen X, Li Y, Wang M, Shen C, Zhang X, Wang Y, Liu $X$, He J. 2015. DEHP exposure impairs mouse oocyte cyst breakdown and primordial follicle assembly through estrogen receptordependent and independent mechanisms. $J$ Hazard Mater, 298:232-240.

Myers M, Morgan FH, Liew SH, Zerafa N, Gamage TU, Sarraj M, Cook M, Kapic I, Sutherland A, Scott CL, Strasser A, Findlay JK, Kerr JB, Hutt KJ. 2014 PUMA regulates germ cell loss and primordial follicle endowment in mice. Reproduction, 148:211-219.

Nilsson EE, Skinner MK. 2009. Progesterone regulation of primordial follicle assembly in bovine fetal ovaries. Mol Cell Endocrinol, 313:9-16.

Padmanabhan V, Veiga-Lopez A. 2013. Sheep models of polycystic ovary syndrome phenotype. Mol Cell Endocrinol, 373:8-20.

Pelosi E, Forabosco A, Schlessinger D. 2015. Genetics of the ovarian reserve. Front Genet, 6:308. doi: 10.3389/fgene.2015.00308

Pepe GJ, Lynch TJ, Albrecht ED. 2013. Regulation of baboon fetal ovarian development by placental estrogen: onset of puberty is delayed in offspring deprived of estrogen in utero. Biol Reprod, 89:132. doi: 10.1095/biolreprod.112.107318.

Pepling ME, Spradling AC. 1998. Female mouse germ cells form synchronously dividing cysts. Development, 125:3323-3328.

Pepling ME, Spradling AC. 2001. Mouse ovarian germ cell cysts undergo programmed breakdown to form primordial follicles. Dev Biol, 234:339-351.

Pepling ME. 2012. Follicular assembly: mechanisms of action. Reproduction, 143:139-49.

Pepling ME. 2016. Development. Nursing the oocyte. Science, 352:35-36.

Perez GI, Robles R, Knudson CM, Flaws JA, Korsmeyer SJ, Tilly JL. 1999. Prolongation of ovarian lifespan into advanced chronological age by Baxdeficiency. Nat Genet, 21:200-203.
Pocar P, Fiandanese N, Berrini A, Secchi C, Borromeo V. 2017. Maternal exposure to $\operatorname{di}(2-$ ethylhexyl)phthalate (DEHP) promotes the transgenerational inheritance of adult-onset reproductive dysfunctions through the female germline in mice. Toxicol Appl Pharmacol, 322:113-121.

Qiu XH, Li ML, Li N, Sun Q, Zhou J, Ma RJ, Lin Y, Xie M, Ge X, Chen L, Yao B. 2017. Maternal diabetes impairs the initiation of meiosis in murine female germ cells. Mol Med Rep, 16:5189-5194.

Quirke LD, Juengel JL, Tisdall DJ, Lun S, Heath DA, McNatty KP. 2001. Ontogeny of steroidogenesis in the fetal sheep gonad. Biol Reprod, 65:216-228.

Rae MT, Palassio S, Kyle CE, Brooks AN, Lea RG, Miller DW, Rhind SM. 2001. Effect of maternal undernutrition during pregnancy on early ovarian development and subsequent follicular development in sheep fetuses. Reproduction, 122:915-922.

Rae MT, Kyle CE, Miller DW, Hammond AJ, Brooks AN, Rhind SM. 2002. The effects of undernutrition, in utero, on reproductive function in adult male and female sheep. Anim Reprod Sci, 72:6371.

Rawlings NC, Evans AC, Honaramooz A, Bartlewski PM. 2003. Antral follicle growth and endocrine changes in prepubertal cattle, sheep and goats. Anim Reprod Sci, 78:259-270.

Reader KL, Haydon LJ, Littlejohn RP, Juengel JL, McNatty KP. 2012. Booroola BMPR1B mutation alters early follicular development and oocyte ultrastructure in sheep. Reprod Fertil Dev, 24:353-361.

Rhind SM, Rae MT, Brooks AN. 2001. Effects of nutrition and environmental factors on the fetal programming of the reproductive axis. Reproduction, 122:205-214

Rodrigues P, Limback D, McGinnis LK, Plancha CE, Albertini DF. 2009. Multiple mechanisms of germ cell loss in the perinatal mouse ovary. Reproduction, 137:709-720.

Ruoss C, Tadros A, O'Shea T, McFarlane J, Almahbobi G. 2009. Ovarian follicle development in Booroola sheep exhibiting impaired bone morphogenetic protein signalling pathway. Reproduction, 138:689-696.

Salvetti NR, Ortega HH, Veiga-Lopez A, Padmanabhan V. 2012. Developmental programming: impact of prenatal testosterone excess on ovarian cell proliferation and apoptotic factors in sheep. Biol Reprod, 87:22, 1-10. doi: 10.1095/biolreprod.112.100024.

Sawyer HR, Smith P, Heath DA, Juengel JL, Wakefield SJ, McNatty KP. 2002. Formation of ovarian follicles during fetal development in sheep. Biol Reprod, 66:1134-1150.

Sloboda DM, Hickey M, Hart R. 2011. Reproduction in females: the role of the early life environment. Hum Reprod Update, 17:210-227.

Smith P, O WS, Hudson NL, Shaw L, Heath DA, Condell L, Phillips DJ, McNatty KP. 1993. Effects of the Booroola gene (FecB) on body weight, ovarian development and hormone concentrations during fetal life. J Reprod Fertil, 98:41-54. 
Smith P, Steckler TL, Veiga-Lopez A, Padmanabhan V. 2009. Developmental programming: differential effects of prenatal testosterone and dihydrotestosterone on follicular recruitment, depletion of follicular reserve, and ovarian morphology in sheep. Biol Reprod, 80:726736

Sominsky L, Ziko I, Soch A, Smith JT, Spencer SJ. 2016. Neonatal overfeeding induces early decline of the ovarian reserve: Implications for the role of leptin. Mol Cell Endocrinol, 431:24-35.

Soyal SM, Amleh A, Dean J. 2000. FIGalpha, a germ cell-specific transcription factor required for ovarian follicle formation. Development, 127:4645-4654.

Spadotto R, Damasceno DC, Godinho AF, Amorim EM, Perobelli JE, Kempinas Wde G. 2012. Reproductive physiology, and physical and sexua development of female offspring born to diabetic dams. Arq Bras Endocrinol Metabol, 56:96-103.

Steckler T, Wang J, Bartol FF, Roy SK, Padmanabhan V. 2005. Fetal programming: prenatal testosterone treatment causes intrauterine growth retardation, reduces ovarian reserve and increases ovarian follicular recruitment. Endocrinology, 146:3185-3193.

Sullivan TM, Micke GC, Greer RM, Irving-Rodgers HF, Rodgers RJ, Perry VE. 2009. Dietary manipulation of Bos indicus $\mathrm{x}$ heifers during gestation affects the reproductive development of their heifer calves. Reprod Fertil Dev, 21: 773-84.

Tang WW, Kobayashi T, Irie N, Dietmann S, Surani MA. 2016. Specification and epigenetic programming of the human germ line. Nat Rev Genet, 17:585-600.

Truman AM, Tilly JL, Woods DC. 2017. Ovarian regeneration: the potential for stem cell contribution in the postnatal ovary to sustained endocrine function. Mol Cell Endocrinol, 445:74-84.

Tsoulis MW, Chang PE, Moore CJ, Chan KA, Gohir W, Petrik JJ, Vickers MH, Connor KL, Sloboda DM. 2016. Maternal high-fat diet-induced loss of fetal oocytes is associated with compromised follicle growth in adult rat offspring. Biol Reprod, 94:94. doi: 10.1095/biolreprod.115.135004

Wang C, Roy SK. 2007. Development of primordial follicles in the hamster: role of estradiol-17beta. Endocrinology, 148:1707-1716.

Wang YY, Sun YC, Sun XF, Cheng SF, Li B, Zhang XF, De Felici M, Shen W. 2017. Starvation at birth impairs germ cell cyst breakdown and increases autophagy and apoptosis in mouse oocytes. Cell Death Dis, 8:e2613. doi: 10.1038/cddis.2017.3.

Weller M, Fortes MRS, Marcondes MI, Rotta PP, Gionbeli TRS, Valadares Filho SC, Campos MM, Silva FF, Silva W, Moore S, Guimaraes SEF. 2016. Effect of maternal nutrition and days of gestation on pituitary gland and gonadal gene expression in cattle. $J$ Dairy Sci, 99:3056-3071.

White YA, Woods DC, Takai Y, Ishihara O, Seki H, Tilly JL. 2012. Oocyte formation by mitotically active germ cells purified from ovaries of reproductive-age women. Nat Med, 18:413-421.
Xu J, Gridley T. 2013. Notch2 is required in somatic cells for breakdown of ovarian germ-cell nests and formation of primordial follicles. BMC Biol, 11:13. doi.org/10.1186/1741-7007-11-13.

Yan C, Wang P, DeMayo J, DeMayo FJ, Elvin JA, Carino C, Prasad SV, Skinner SS, Dunbar BS, Dube JL, Celeste AJ, Matzuk MM. 2001. Synergistic roles of bone morphogenetic protein 15 and growth differentiation factor 9 in ovarian function. $\mathrm{Mol}$ Endocrinol, 15:854-866.

Yang MY, Fortune JE. 2008. The capacity of primordial follicles in fetal bovine ovaries to initiate growth in vitro develops during mid-gestation and is associated with meiotic arrest of oocytes. Biol Reprod, 78:1153-1161.

Yu N, Roy SK. 1999. Development of primordial and prenatal follicles from undifferentiated somatic cells and oocytes in the hamster prenatal ovary in vitro: effect of insulin. Biol Reprod, 61:1558-1567.

Zachos NC, Billiar RB, Albrecht ED, Pepe GJ. 2002. Developmental regulation of baboon fetal ovarian maturation by estrogen. Biol Reprod, 67:1148-1156.

Zachos NC, Billiar RB, Albrecht ED, Pepe GJ. 2004. Regulation of oocyte microvilli development in the baboon fetal ovary by estrogen. Endocrinology, 145:959-966.

Zamboni L, Bézard J, Mauléon P. 1979. The role of the mesonephros in the development of the sheep fetal ovary. Ann Biol Anim Biochim Biophys, 19:1153-1178.

Zambrano E, Guzman C, Rodriguez-Gonzalez GL, Durand-Carbajal M, Nathanielsz PW. 2014. Fetal programming of sexual development and reproductive function. Mol Cell Endocrinol, 382:538-549.

Zhang H, Liu L, Li X, Busayavalasa K, Shen Y, Hovatta O, Gustafsson JA, Liu K. 2014. Life-long in vivo cell-lineage tracing shows that no oogenesis originates from putative germline stem cells in adult mice. Proc Natl Acad Sci USA, 111:17983-17988.

Zhang XF, Zhang T, Han Z, Liu JC, Liu YP, Ma JY, Li L, Shen W. 2015. Transgenerational inheritance of ovarian development deficiency induced by maternal diethylhexyl phthalate exposure. Reprod Fertil Dev, 27:1213-1221.

Zhao L, Du X, Huang K, Zhang T, Teng Z, Niu W, Wang C, Xia G. 2016. Rac1 modulates the formation of primordial follicles by facilitating STAT3-directed Jagged1, GDF9 and BMP15 transcription in mice. Sci Rep, 6:23972. doi:10.1038/srep23972.

Zheng W, Zhang H, Gorre N, Risal S, Shen Y, Liu K. 2014a. Two classes of ovarian primordial follicles exhibit distinct developmental dynamics and physiological functions. Hum Mol Genet, 23:920-928.

Zheng W, Zhang H, Liu K. 2014b. The two classes of primordial follicles in the mouse ovary: their development, physiological functions and implications for future research. Mol Hum Reprod, 20:286-292.

Zou K, Yuan Z, Yang Z, Luo H, Sun K, Zhou L, Xiang J, Shi L, Yu Q, Zhang Y, Hou R, Wu J. 2009. Production of offspring from a germline stem cell line derived from neonatal ovaries. Nat Cell Biol, 11:631-636. 